\section{An Automated Cost-effective System for Real-time Slope Mapping in Commercial Wild Blueberry Fields}

\author{
Qamar Uz Zaman ${ }^{1,3}$, Arnold Walter Schumann², and \\ David Charles Percival ${ }^{1}$
}

AdDitional INDEX wORDs. accelerometer, DGPS, GIS, precision agriculture, tilt sensor, Vaccinium angustifolium

SUMmARY. The development of site-specific agriculture has increased the need for knowledge regarding within-field variability in factors such as soil/plant characteristics and topography that influence wild blueberry (Vaccinium angustifolium) production. Surface soil properties are the first type of information most frequently used by blueberry producers in developing management plans. Topographic features are not yet routinely used to guide within-field management. The majority of blueberry fields in eastern Canada have gentle to severe topography. An automated slope measurement and mapping system (SMMS) consisting of low-cost accelerometers used as tilt sensors, differential global positioning system (DGPS), and laptop and custom software was developed. The SMMS was mounted on an all-terrain vehicle for real-time slope measurement and mapping. Six commercial wild blueberry fields were surveyed in central Nova Scotia to evaluate the performance of SMMS. The automatically sensed slopes (SS) were also compared with manually measured slopes (MS) at 20 randomly selected points in each field to examine the accuracy of SMMS. The SMMS measured slope reliably in the selected fields with root mean square error ranging from 0.12 to 0.56 degrees and correlations of SS with MS of $R^{2}=0.95$ to 0.99 . The selected fields had substantial variation in slope (ranging from 0.8 to 31.0 degrees). Therefore, the use of low-cost and reliable accelerometers with a DGPS is a better option than expensive real-time kinematic DGPS for developing cost-effective SMMS to quantify and map slopes (real-time) for planning site-specific management practices in commercial fields. The SS maps or real-time SMMS could also be used to adjust vehicle speed at particularly steep slopes.

$\mathrm{W}$ ild blueberry fields are developed from native stands on deforested farmland by removing competing vegetation (Eaton, 1988). The crop is native to northeastern North America. The majority of fields are situated in acidic soils $(\mathrm{pH}<$ 5 ) that are low in mineral nutrients and have poor water holding capacities, significant bare spots, weed patches, and gentle to severe topography (Trevett, 1962). The substantial variation in soil/plant characteristics, topographic features, and fruit yield

\footnotetext{
This work was supported by the Oxford Frozen Foods Limited, by Agri Futures Nova Scotia, by the Wild Blueberry Producers Association of Nova Scotia, and by the Nova Scotia Department of Agriculture Technology Development Program.

We thank Gary Brown and Doug Wyllie (farm managers, Bragg Lumber Company), Travis Esau (research assistant), and Scott Read (research technician) for their assistance during the experiment.

${ }^{1}$ Nova Scotia Agricultural College, 39 Cox Road, P.O. Box 550 Truro, B2N 5E3, Nova Scotia, Canada

${ }^{2}$ University of Florida, IFAS, Citrus Research and Education Center, 700 Experiment Station Road, Lake Alfred, FL 33850

${ }^{3}$ Corresponding author. E-mail: qzaman@nsac.ca.
}

within blueberry fields emphasizes the need for precise site-specific crop management to maximize profit and minimize environmental impacts (Malay, 2000; Zaman et al., 2009).

Soil surface properties are a critical component used by producers in developing wild blueberry management plans (Yarborough, 2004). Topographic features are not yet routinely used to guide within-field management and to control erosion in wild blueberry fields. Traditionally, agrochemicals are applied uniformly without considering the substantial variation in soil/plant characteristics, topographic features, and crop yield with-in fields (Percival and Sanderson, 2004). Over-fertilization in lower slope areas may deteriorate water quality and reduce profit, while under-fertilization in steep slope areas may restrict crop yield (Zaman et al., 2009). The risk of nutrient runoff from soils increases with the steepness of the slope. Spatial mapping of topography, soil properties, and fruit yield could help to manage the field inputs in a site-specific fashion. There is extensive literature in other crops that suggests the possibility of using topography to delineate practical, agronomic meaningful field management zones (Beckie et al., 1997; Corre et al., 1996; Franzen et al., 1998; Hanna et al., 1982; Vitharana et al., 2008; Wibawa et al., 1993). Several researchers have concentrated on the measurement and mapping of topographic features using different techniques for site-specific application of agrochemicals and irrigation in agronomic crops (Jenson and Domingue, 1988; Kravchenko and Bullock, 2002; McConkey, et al., 1997; Moore et al., 1991). Pennock et al. (2001) delineated a canola (Brassica napus) field into nitrogen management zones based on variations in elevation using a digital elevation model (DEM). Iqbal et al. (2005) used a real-time kinematicsglobal positioning system (RTKGPS) and a geographic information system (GIS) to derive topographic features and relate them with hydrologic attributes in a corn (Zea mays) field. Remote sensing is another option to estimate slope variations within a field. Renschler and Flanagan (2008) analyzed the impact of the accuracy of six alternative topographical data sources on predicting soil erosion rates using a water erosion prediction project model. They demonstrated that commonly available topographic data sources (e.g., U.S. Geological Survey topographic contour lines and/or digital elevation digital elevation models) are insufficiently accurate in their topographical representation of watershed boundaries, slopes, and upslope contributing areas to be able to meaningfully apply detailed process-based soil erosion assessment tools at the

\begin{tabular}{llll}
\hline $\begin{array}{l}\text { Units } \\
\begin{array}{l}\text { To convert U.S. to SI, } \\
\text { multiply by }\end{array}\end{array}$ & U.S. unit & SI unit & $\begin{array}{l}\text { To convert SI to U.S., } \\
\text { multiply by }\end{array}$ \\
\hline 0.4047 & $\mathrm{acre}(\mathrm{s})$ & $\mathrm{ha}$ & 2.4711 \\
0.3048 & $\mathrm{ft}$ & $\mathrm{m}$ & 3.2808 \\
0.5144 & $\mathrm{knot}(\mathrm{s})$ & $\mathrm{m} \cdot \mathrm{s}^{-1}$ & 1.9438 \\
0.4470 & $\mathrm{mph}$ & $\mathrm{m} \cdot \mathrm{s}^{-1}$ & 2.2369
\end{tabular}


field scale. A survey-grade RTK-GPS was more accurate than survey maps and DEM. However, these techniques are expensive and data processing is also intensive and complicated. Therefore, there is a need to develop a costeffective system using reliable and inexpensive sensors for real-time measurement and mapping of topography in wild blueberry fields.

The widespread availability of accurate DGPS, low-cost and reliable sensors such as accelerometers since 2000, and the rapid evolution of laptop computing power offers new opportunities for field-scale measurement and mapping of topographic features. Several researchers have been using accelerometers for field-scale tilt measurements (Jeon et al., 2004; Powers et al., 2000; Vellidis et al., 2001). There are several advantages in the use of accelerometers as tilt sensors; they are cheap, small in size, reliable, and have a fast response time. These features make this type of sensor ideal for field-scale slope mapping (Barbosa et al., 2007; Spencer and Owen, 1981).

Therefore, the objective of this study was to develop and test a costeffective automated system for realtime slope measurement and mapping in commercial wild blueberry fields.

\section{Material and methods}

Hardware DEvelopment For SLOPE MEASUREMENT AND MAPPING SYSTEM (SMMS). A tilt sensor was developed from two two-axis thermal accelerometers (Memsic 2125; Parallax, Rocklin, CA) to permit sensing the tilt of a vehicle in any orientation on a slope. The configuration uses two accelerometers mounted with their X-Y planes perpendicular to each other in a custom plastic enclosure. The tilt sensor was mounted on an all-terrain vehicle (ATV) nominally $0.3 \mathrm{~m}$ aboveground level (Fig. 1). The ATV was driven at an average speed of about $2 \mathrm{~m} \cdot \mathrm{s}^{-1}$ following 10 $\mathrm{m}$-spaced gridlines on a ProMark3 mobile mapper (Thales Navigation, Santa Clara, CA) also mounted on the ATV (Fig. 1). The gridlines within the boundary of each field were created in Arcview GIS 3.2 (ESRI, Redland, CA) using the extension "Orchard" (Lincoln Ventures, Hamilton, New Zealand) and imported into the ProMark3 mobile mapper. The reason for using the mobile mapper to follow the gridlines is that wild blueberry fields have
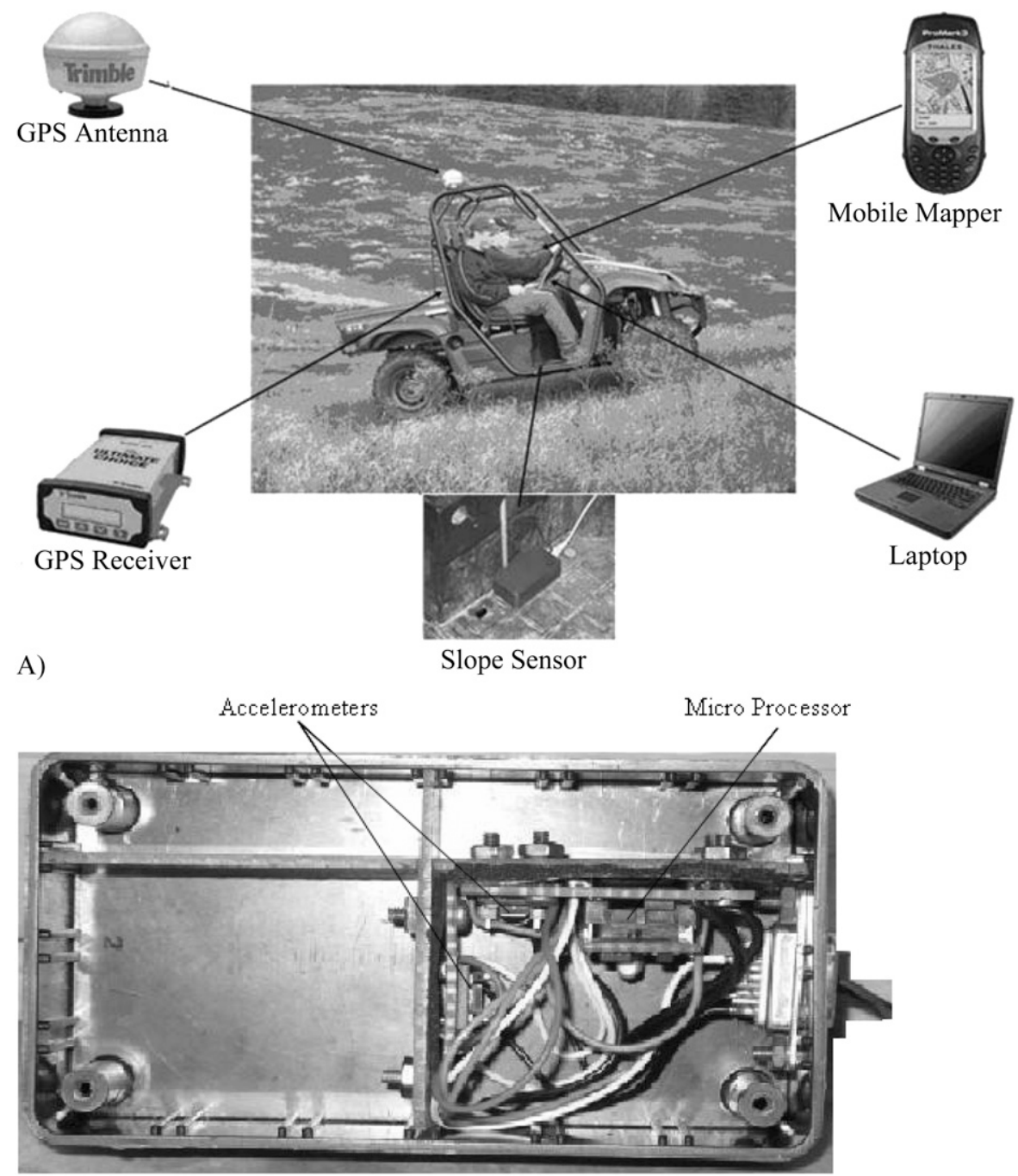

B)

Fig. 1. (A) Integration of an automated system for real-time slope measurement and mapping in wild blueberry fields (GPS = global positioning system). (B) Configuration of the slope sensor using accelerometers and microprocessor.

no rows or tramlines for guiding the vehicle.

The accelerometers' pulse width modulation outputs for their $\mathrm{X}$ and $\mathrm{Y}$ axes were processed by a BasicX-24 microcontroller (Netmedia, Tucson, AZ), which used software algorithms to convert the force vectors to angles of tilt. Thus, the microcontrolleraccelerometer assembly was configured to continuously measure the tilt of the vehicle and therefore the slope of the terrain at any orientation in the $\mathrm{X}-\mathrm{Y}$ plane. The tilt data from the microcontroller was continuously transmitted through a serial RS-232 port to a laptop computer. Software on the laptop computer sampled the tilt data at preset distances while moving over the ground with the ATV.
The sample locations were determined by a DGPS antenna (AgGPS-332; Trimble Navigation, Sunnyvale, CA) mounted on the ATV above the tilt sensor. The laptop computer also collected DGPS position ( $\mathrm{x}$ and $\mathrm{y}$ coordinates) and ground speed data in an Access database (Microsoft, Redmond, WA) (Fig. 1). The ground speed (in knots) was parsed from the DGPS string and converted to metric units using: speed $($ knots $) \times 0.51444=$ speed (meters per second). The DGPS receiver was configured for a $10-\mathrm{Hz}$ acquisition rate using U.S. Coast Guard beacons for differential correction.

The integrated tilt sensorDGPS-computer-ATV system, therefore, was able to collect georeferenced terrain slope data in real time. 
Software InTerface. The custom software for reading DGPS and tilt sensor output, calculating slope, and storing the data in a central database was written in Delphi 5.0 (Borland Software, Scotts Valley, CA) for a 32-bit Windows operating system (Microsoft). The software incorporated configuration, setup, and monitoring features on the main data collection page, to select the computer hardware, and to diagnose the correct operation of the slope and DGPS (Fig. 2). Tilt sensor data output was continuously plotted on the main screen of the software. Realtime on-screen updates of ground speed were used to manually adjust the vehicle's speed to the target speed, and the measured slope was also displayed in real-time at $\mathrm{l} \mathrm{Hz}$ (Fig. 2). The slope (degrees) was calculated in real-time, using the following formula in the custom developed software:

$$
\begin{aligned}
\text { Slope }= & \cos ^{-1}\left\{\cos \left(\theta_{\mathrm{x}}\right) \cos \left(\theta_{\mathrm{y}}\right) /\left[\cos ^{2}\left(\theta_{\mathrm{y}}\right)\right.\right. \\
& \sin ^{2}\left(\theta_{\mathrm{x}}\right)+\cos ^{2}\left(\theta_{\mathrm{x}}\right) \sin ^{2}\left(\theta_{\mathrm{y}}\right) \\
& \left.\left.+\cos ^{2}\left(\theta_{\mathrm{x}}\right) \cos ^{2}\left(\theta_{\mathrm{y}}\right)\right]^{1 / 2}\right\}
\end{aligned}
$$

where

$\theta_{\mathrm{x}}$ is the slope of the $\mathrm{x}$-axis of the

slope sensor at the time of reading,

$\theta_{y}$ is the slope of the $y$-axis of the

slope sensor at the time of reading.

The database table could be easily viewed in the "Database" page of the program (Fig. 2). The tilt sensor (slope sensor) could be calibrated using the option "calibrate" on the main screen of the software before taking the measurements in the field. Slope data, together with matching coordinates, could then be viewed and easily exported by copying to the Windows clipboard and pasting to a spreadsheet or GIS program for further processing or mapping.

REAL-TIME PERFORMANCE TESTS AND DATA ANALYSIS. The performance of the SMMS (software and hardware) was assessed by measuring the tilt angle (slope, in degrees) in a number of different wild blueberry fields. For this study, six fields located in Colchester County, central Nova Scotia, were selected for testing the accuracy of the SMMS: four fields $(\mathrm{Fl}=2.97$ ha, F2 = 1.49 ha, F3 = 1.49 ha, and $\mathrm{F} 4=0.53 \mathrm{ha}$ ) at Truro [site 1 (lat. $45.3656^{\circ} \mathrm{N}$, long. $\left.\left.-63.2143^{\circ} \mathrm{W}\right)\right]$ and two fields (F5 $=3.09$ ha and F6 = $1.07 \mathrm{ha}$ ) at Londonderry [site 2 (lat. $45.4831^{\circ} \mathrm{N}$, long. $\left.\left.-63.5748^{\circ} \mathrm{W}\right)\right]$. These fields have gentle to severe slopes. Both fields were in their crop year of the biennial crop production cycle in 2008, having been in the vegetative sprout year in 2007 . These fields have been under commercial management over the past decade and have received biennial pruning by mowing for the past several years along with conventional fertilizer, weed, and disease management practices. There were no rows or tramlines in wild blueberry fields. Land surveys in four fields were conducted from 13 to 14 Oct. 2007 to map variation in

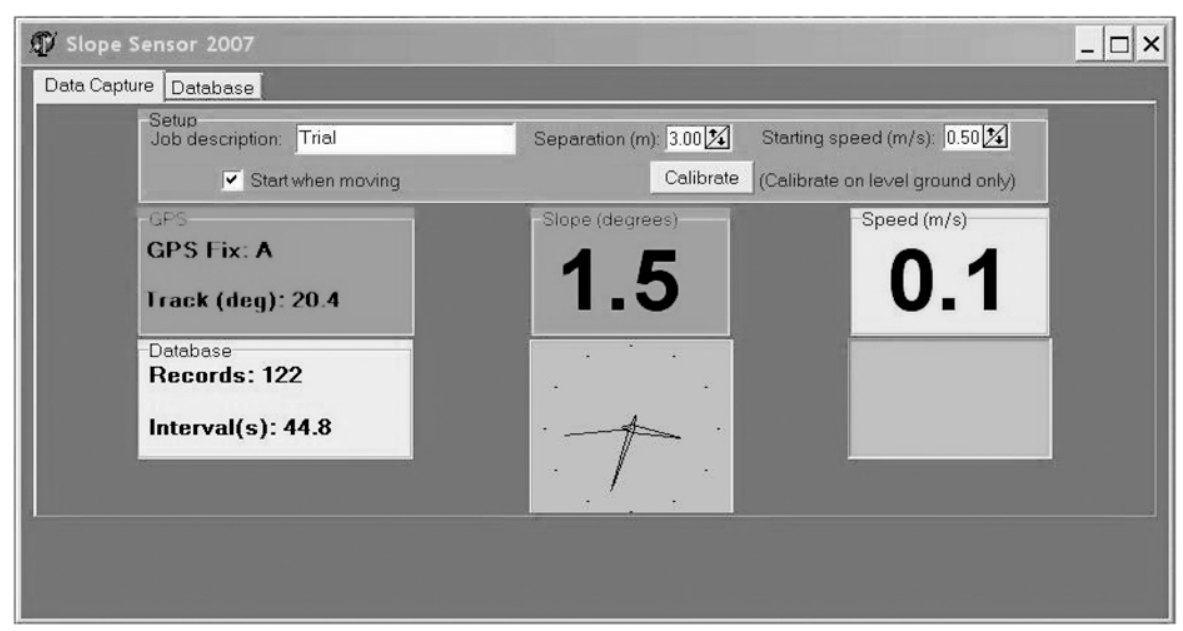

Fig. 2. Windows software (Microsoft, Redmond, WA) user interface showing controls, slope sensor and differential global positioning system (DGPS) diagnostics, ground speed, and real-time slope data $\left(1 \mathrm{~m}=3.2808 \mathrm{ft}, 1 \mathrm{~m} \cdot \mathrm{s}^{-1}=2.2369 \mathrm{mph}\right)$. slope within the fields. Two fields in Londonderry, NS, were mapped to obtain slope variability on 13 May 2008. The tilt sensor was calibrated on a level ground surface ( 0 degree slope) before taking the measurements. Actual ground speed, monitored on the main software screen during the surveys (Fig. 2), was maintained at about $2 \mathrm{~m} \cdot \mathrm{s}^{-1}$. The slope data and corresponding DGPS ( $\mathrm{x}$ and $\mathrm{y}$ coordinates) were collected at $3-\mathrm{m}$ intervals and stored on the laptop computer. To assess the accuracy of SMMS, the SS were correlated with MS at 20 randomly selected data points in each field. These points were selected randomly in each field to cover the representative slope variability within fields. The sampling points were marked with a ProMark3 mobile mapper. The slope angle was measured manually at the 20 selected points in each field with a digital level (Craftsman SmartTool Plus; Sears, Hoffman Estates, IL). Five slope measurements were made at each selected point within a radius of $1 \mathrm{~m}$ and were averaged to obtain the representative slope of that point. A bubble level was used with the craftsman digital level to find the contour of the slope and to align the digital level perpendicular to the contour for measuring the maximum slope at a selected point.

The datasets (SS and MS at selected points) of all fields were analyzed using classical statistical techniques with SAS (version 9.1; SAS Institute, Cary, NC) to obtain minimum, maximum, and mean values. The SS and MS of selected points in each field were compared by the $t$ test at a $5 \%$ level of significance. The linear regression method was used to test the relationship between SS and MS of selected points. The coefficients of determination $\left(R^{2}\right)$ and root mean square error (RMSE) were calculated to examine the performance of the system using SAS and Excel (Office 2000, Microsoft) spreadsheets. The parallel curve analysis was performed with Genstat 5.0 (Lawes Agricultural Trust, Rothamsted, UK) to test whether individual sites needed separate equations to describe the relationship between sensor and manual angles. The survey data files of DGPS, MS, and MS were imported into ArcView 3.2 GIS software for mapping. Interpolated SS surfaces were obtained using a kriging interpolation 
technique. The elevation contour maps were overlaid on a smoothed SS maps for comparison (GeoNova, 2009).

\section{Results and discussion}

The system performed reliably during these surveys, permitting real-time measurement, calculation, presentation, and storage of slope data. The software permitted accelerated processing of sensor data (parsing, sorting, and calculating). This software interface required no postprocessing of data. The graphical user interface allowed monitoring of speed, tilt sensor, and DGPS function during a survey so that errors could be quickly identified and corrected. Average actual ground speed during the surveys was $1.8 \pm 0.2 \mathrm{~m} \cdot \mathrm{s}^{-1}$. Each field survey took about $25,16,20,6,26$, and 9 min to complete, and collected $1107,715,862,242,1150$, and 400 slope measurements in the fields $\mathrm{Fl}$, F2, F3, F4, F5, and F6, respectively.

The MS were significantly correlated with SS $\left(R^{2}=0.98-0.99\right.$; RMSE $=0.11-0.57$ degrees $)$ in the selected fields. The difference between MS and SS could be influenced by the accuracies of SMMS and manual measurements. Non-significance of the $t$ tests indicated that there was no bias in the MS and SS (Table 1). The parallel curve analysis showed that individual equations were not significantly different in the intercept and slope. Therefore, only one equation for all sites could be used to describe the relationship between sensor and manual angles (Fig. 3). The results indicated that low-cost, accurate accelerometers were needed as tilt sensors to develop SMSS for reliable real-time measurement and mapping of slope variations within wild blueberry fields. Therefore, the use of low-cost and reliable accelerometers (\$200) with a Trimble AgGPS332 (\$3100) may be a better option than expensive RTK-DGPS (ranging from $\$ 25,000$ to $\$ 60,000$; depending upon the accuracy) for developing cost-effective SMMS to quantify and map slopes (real-time) for planning site-specific management practices in commercial fields.

The SS raw data for each selected field were mapped in Arcview 3.2 (Fig. 4). Due to space constraints, the maps of site 1 [Fl-F4 (Figs. 4 and 5)] are presented as an example.

There was substantial variation in slope within each field (Fig. 4). The slope varied from 0.8 to 31.0 degrees in the selected fields. The slopes in each field were divided into five classes: very low (0-6 degrees), low (6.112 degrees), moderate (12.1-18 degrees), steep (18.1-24 degrees), and very steep (24.1-30 degrees). The plants in steep slope (>18 degrees) areas would receive less fertilizer and plants in low-lying areas (slope $<12$ degrees) would receive excess fertilizer with uniform application of agrochemicals (Zaman et al., 2009).
The reason might be that nutrients runoff from steep slope areas to lowlying areas within fields. Wild blueberry crops are low-input systems with a narrow optimal window of plant nutrients; detrimental effects of excess $\mathrm{N}$ occur when too much $\mathrm{N}$ is applied in low-lying areas of the field (i.e., the excess floral bud numbers and harvestable yields). Unnecessary or over-fertilization in lowlying areas may also deteriorate water quality, promote increased weed growth, and increase production cost. Under-fertilization restricts yield and can reduce berry quality (Percival and Sanderson, 2004; Zaman et al., 2009). The substantial variation in slope within the field emphasized the need for the field-scale measurement and mapping of slopes. These maps could be used to develop appropriate management zones based on slope variation for variable rate application of agrochemicals within wild blueberry fields.

A smoothed map of slopes developed by interpolation of individual measured SS identified contiguous classified zones of the fields where slopes were different (Fig. 5). The elevation contour maps were overlaid on the SS maps. The kriged SS maps for the wild blueberry fields have better resolution than the elevation contour maps. Some of the withinfield slope variation in highly variable fields is lost when using elevation contour maps due to the low resolution

Table 1. Summary statistics for determining the accuracy of slope angle measurements with an automated system (SS) relative to the manual reference measurements (MS) of 20 selected points in each of six fields (F1-F6) in central Nova Scotia, Canada: Truro (F1-F4) and Londonderry (F5 and F6).

\begin{tabular}{|c|c|c|c|c|c|c|c|c|c|}
\hline \multicolumn{10}{|c|}{ Site 1: Truro } \\
\hline Field $^{\mathrm{z}}$ & Mean (degrees) & Max (degrees) ${ }^{y}$ & Min (degrees) ${ }^{\mathrm{y}}$ & Calibration equations & $\mathbf{R}^{2}$ & $\mathrm{RMSE}^{\mathrm{y}}$ & $t$ & df & $P>\mathrm{F}$ \\
\hline MSF1 & 12.6 & 30.1 & 1.2 & $y=1.0214 x+0.0216$ & 0.995 & 0.570 & -0.108 & 38 & 0.914 \\
\hline MSF2 & 10.1 & 20.8 & 0.9 & $y=1.0218 x-0.130$ & 0.990 & 0.135 & -0.059 & 38 & 0.953 \\
\hline SSF2 & 10.2 & 21.4 & 1.1 & & & & & & \\
\hline MSF3 & 12.8 & 30.3 & 1.3 & $y=0.9861 x+0.1916$ & 0.995 & 0.111 & -0.005 & 38 & 0.996 \\
\hline SSF4 & 8.0 & 13.4 & 3.5 & & & & & & \\
\hline \multicolumn{10}{|c|}{ Site 2: Londonderry } \\
\hline MSF5 & 11.97 & 26.2 & 1.3 & $y=0.9904 x+0.343$ & 0.994 & 0.207 & 0.079 & 38 & 0.934 \\
\hline SSF5 & 12.15 & 27.2 & 1.1 & & & & & & \\
\hline MSF6 & 11.24 & 23.9 & 0.7 & $y=1.0229 x+0.1725$ & 0.996 & 0.456 & 0.201 & 38 & 0.841 \\
\hline
\end{tabular}

${ }^{\mathrm{z}} \mathrm{MSF}=$ manually measured slope of the field, $\mathrm{SSF}=$ sensed-slope of the field.

${ }^{\mathrm{y}} \mathrm{Mean}=$ mean slope angle, $\mathrm{Max}=$ maximum slope angle, $\mathrm{Min}=$ minimum slope angle, $\mathrm{RMSE}=$ root mean square error 
(Fig. 5). The substantial low lying areas $(\mathrm{F} 1=76 \%, \mathrm{~F} 2=85 \%, \mathrm{~F} 3=$ $58 \%, \mathrm{~F} 4=89 \%, \mathrm{~F} 5=70 \%$, and $\mathrm{F} 6=$ $79 \%)$ and the areas with steep slope of

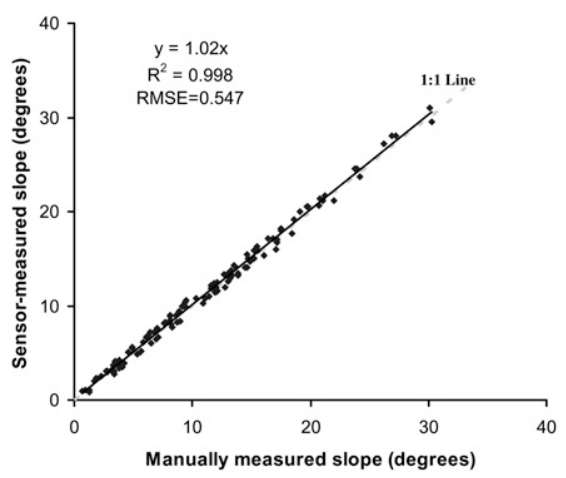

Fig. 3. Relationship between manually measured slope and slopes measured with sensor at selected points in six fields in central Nova Scotia, Canada ( $\mathrm{RMSE}=$ root mean square error). each field $(\mathrm{F} 1=8 \%, \mathrm{~F} 2=3 \%, \mathrm{~F} 3=$ $11 \%$, F5 $=1 \%$, and F6 = 4\%) (Table 2) emphasize the need for the development of cost-effective SMMS to measure and map slope variability in wild blueberry fields. Accurate, reliable measurement and mapping of slope with SMMS is useful to produce prescription maps for precise site-specific application of agrochemicals within wild blueberry fields.

The existing pesticide sprayers used in wild blueberry are able to manually change spray rates within fields at variable slopes (gentle to very steep slopes). The operator can use these slope maps as a guide for accurate application of agrochemicals by changing spray rates at particular slopes in wild blueberry fields with highly variable slopes. The SMMS could also be incorporated into the farm vehicle to automatically control pesticide spray rates according to the terrain slope in real time. Additionally, the operator can adjust ground speed of the field vehicles (sprayer, fertilizer spreader, and harvester) using SS maps obtained by SMMS easily and automatically to avoid accidents.

The SMMS can be incorporated into standard equipment (sprayer and spreader) for real-time slope sensing within blueberry field with the help of commercial developers/manufacturers. The SMMS was sufficiently accurate for many site-specific or precision agriculture uses. Applications of the system could include the real-time determination of slope for on-the-go variable rate fertilization and herbicide spraying. Real-time determination of slope within fields using accelerometers as a tilt sensor is also suggested as a means whereby a driver could judge whether he could travel in safety on a particular slope (Spencer and Owen, 1981).

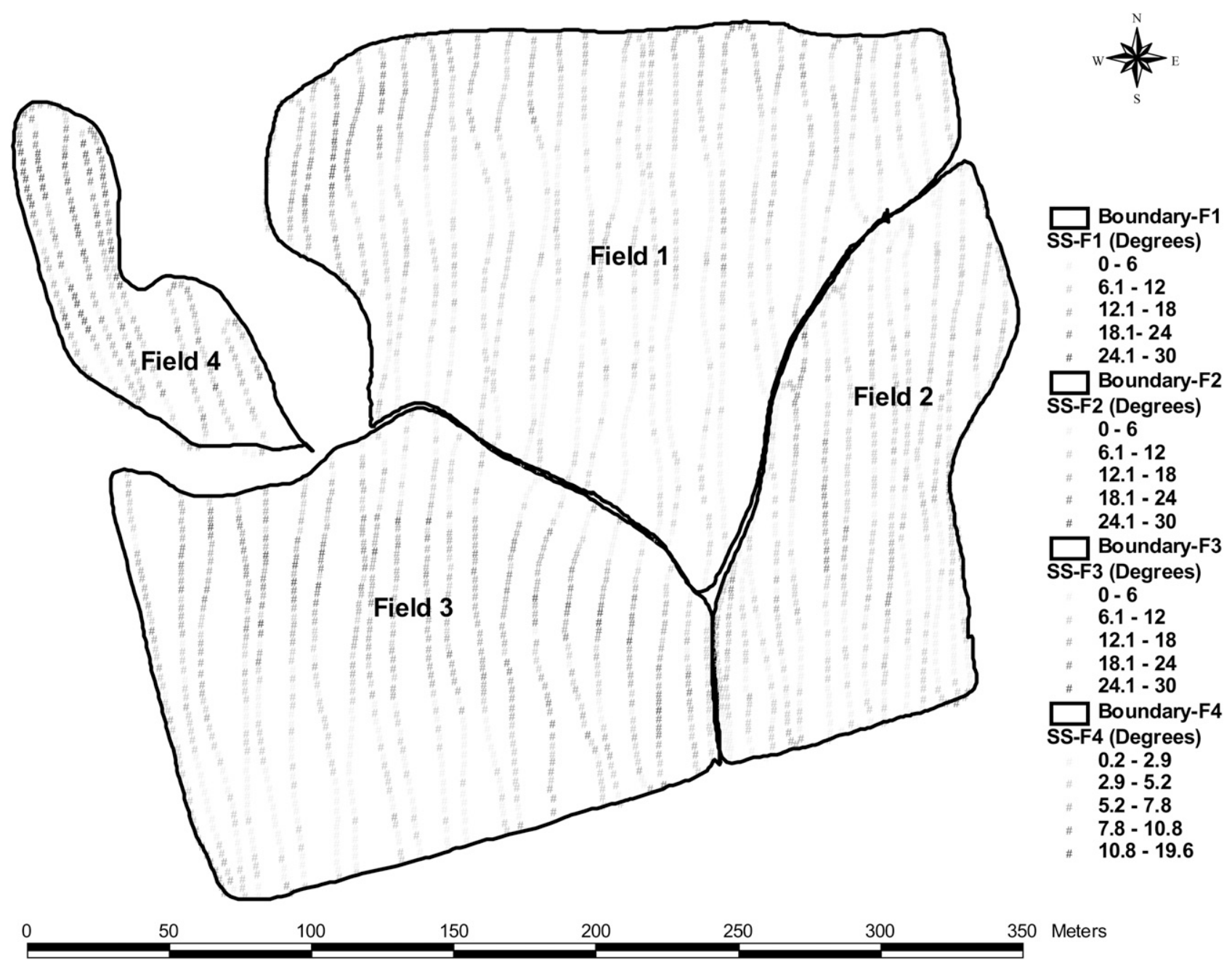

Fig. 4. Geographic information system (GIS) map of slope angle raw data measured automatically (SS) with automated slope measurement and mapping system in four wild blueberry fields $(\mathrm{Fl}-\mathrm{F} 4)$ in central Nova Scotia, Canada $(1 \mathrm{~m}=3.2808 \mathrm{ft})$. 


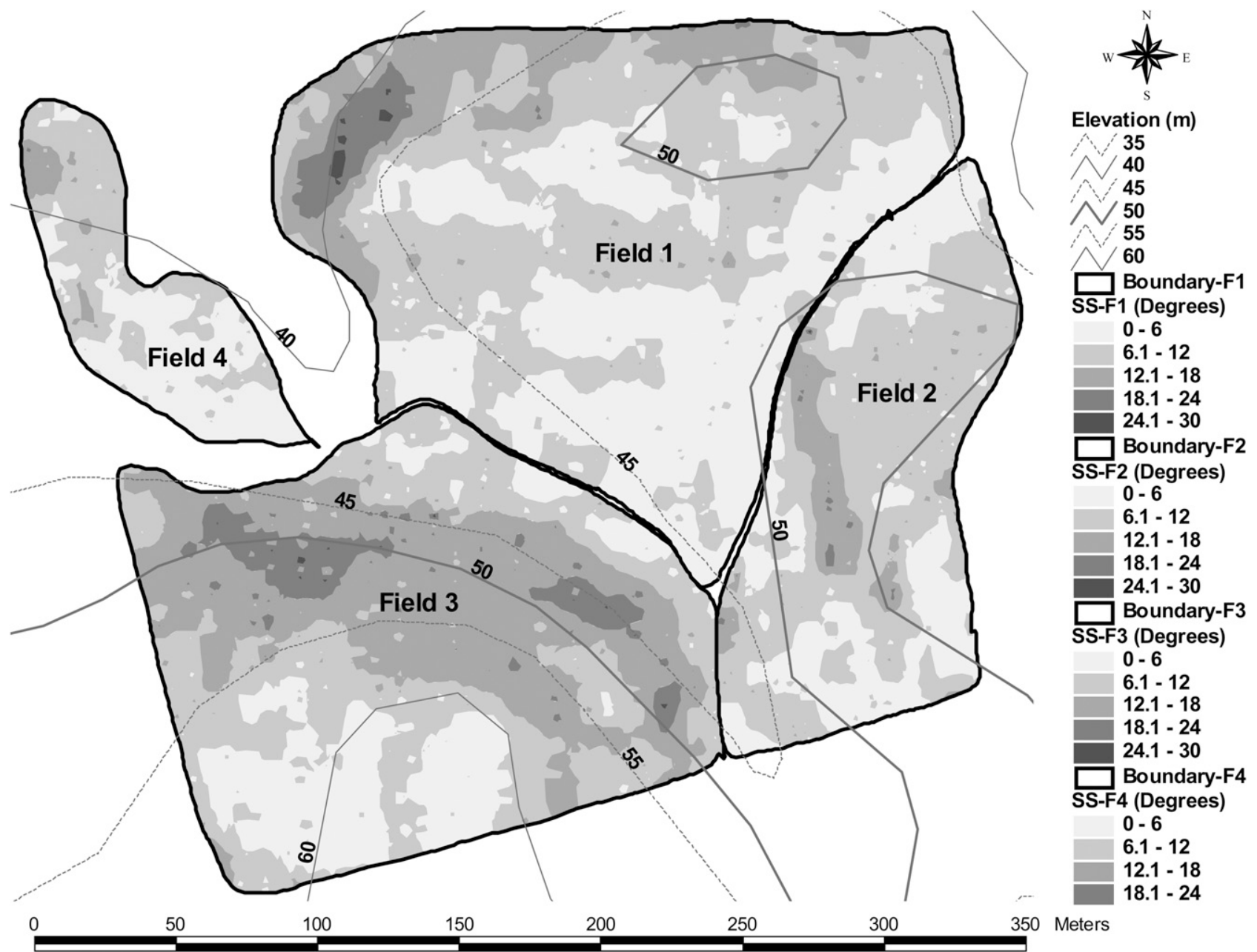

Fig. 5. Interpolated kriged maps of slope angles measured automatically (SS) with the slope measurement and mapping system and elevation contour maps for four of wild blueberry fields (Fl-F4) in central Nova Scotia, Canada $(1 \mathrm{~m}=3.2808 \mathrm{ft})$.

Table 2. The percentage of total field area lying in the regions having very low (0-6 degrees), low (6.1-12 degrees), moderate (12.1-18 degrees), steep (18.1-24 degrees), and very steep (24.1-30 degrees) slopes in each of six fields (F1-F6) in central Nova Scotia, Canada.

\begin{tabular}{lcccccc}
\hline & & \multicolumn{5}{c}{ Area in slope classes (\%) } \\
\cline { 3 - 7 } Field & Total area (ha) & Very low & Low & Moderate & Steep & Very steep \\
\hline F1 & 2.97 & 32.6 & 43.4 & 15.5 & 7.2 & 1.3 \\
F2 & 1.40 & 40.3 & 44.5 & 12.3 & 2.9 & 0 \\
F3 & 2.54 & 26.1 & 32.3 & 30.3 & 9.4 & 1.9 \\
F4 & 0.53 & 45.9 & 42.7 & 11.3 & 0 & 0 \\
F5 & 3.09 & 25.0 & 45.5 & 22.5 & 1.0 & 0 \\
F6 & 1.08 & 36.0 & 43.0 & 17.5 & 3.5 & 0 \\
\hline
\end{tabular}

${ }^{2} 1 \mathrm{ha}=2.4711$ acres

\section{Conclusions}

It is concluded that the inexpensive, accurate, reliable, small size, and light weight accelerometers could be used as tilt sensors to develop the SMMS. The SMMS was sufficiently accurate to measure and map slope rapidly and reliably in selected wild blueberry fields. Therefore, it is proposed that wild blueberry fields should be surveyed to measure and map slope with a SMMS. The slope map could be used to generate prescription maps for precise site-specific application of agrochemicals in the fields to improve horticultural profitability and environmental protection. The slope maps can also be used for safety reasons during field operations by adjusting the vehicle's speed at particular slopes.

\section{Literature cited}

Barbosa, R.N., J.B. Wilkerson, D.C. Yoder, and H.P. Denton. 2007. Different sensing techniques for geomorphometric measurements. Comput. Electron. Agr. 59:13-20.

Beckie, H.J., A.P. Moulin, and D.J. Pennock. 1997. Strategies for variable rate nitrogen fertilization in hummocky terrain. Can. J. Soil Sci. 77:589-595.

Corre, M.D., C. van Kessel, and D.J. Pennock. 1996. Landscape and seasonal patterns of nitrous oxide emissions in a semiarid region. Soil Sci. Soc. Amer. J. 60:1806-1815.

Eaton, L.J. 1988. Nitrogen cycling in lowbush blueberry stands. PhD Diss., Dalhousie Univ., Halifax, NS, Canada.

Franzen, D.W., L.J. Cihacek, V.L. Hofman, and L.J. Swenson. 1998. Topography based 
sampling compared with grid sampling in the northern Great Plains. J. Prod. Agr. 11:364-370.

GeoNova. 2009. Geographic gateway Nova Scotia. 25 Aug. 2009. <http://142.176.62. $103 /$ servlet $/$ translationServlet SSFunction= prepareFetch $>$.

Hanna, A., P. Harlan, and D. Lewis. 1982. Soil available water as influenced by landscape position and aspect. Agron. J. 74:999-1004.

Iqbal, J., J.B. Read, A.J. Thomasson, and J.N. Jenkins. 2005. Relationship between soil landscape and dryland cotton lint yield. Soil Sci. Soc. Amer. J. 69:18721882.

Jeon, H.Y., A.R. Womac, J.B. Wilkerson, and W.E. Hart. 2004. Spray boom instrumentation for field use. Trans. Amer. Soc. Agr. Eng. 47:659-666.

Jenson, S.K. and J.O. Domingue. 1988. Extracting topographic structure from digital elevation data for geographic information system analysis. Photogramm. Eng. Remote Sensing 54:1593-1600.

Kravchenko, A.N. and D.G. Bullock. 2002. Spatial variability of soybean quality data as a function of field topography: I. Spatial data analysis. Crop Sci. 42:804815.

Malay, W.J. 2000. Spatial variability and yield monitor evaluation for carrots and wild blueberries. MS Thesis, Dalhousie Univ., Halifax, NS, Canada.
McConkey, B.G., D.J. Ulrich, and F.B. Dyck. 1997. Slope position and subsoiling effects on soil water and spring wheat yield. Can. J. Soil Sci. 77:83-90.

Moore, I.D., R.B. Grayson, and A.R. Ladson. 1991. Digital terrain modeling: A review of hydrological, geomorphologic and biological applications. Hydrol. Process. 5:3-30.

Pennock, D., F. Walley, M. Solohub, B. Si, and G. Hnatowich. 2001. Topographically controlled yield response of canola to nitrogen fertilizer. Soil Sci. Soc. Amer. J. 65:1836-1845.

Percival, D.C. and K.R. Sanderson. 2004. Main and interactive effects of vegetative year applications of nitrogen, phosphorous and potassium fertilizer. Small Fruits Rev. 3:105-122.

Powers, J.R., J.R. Harris, J.R. Etherton, K.A. Snyder, M. Ronaghi, and B.H. Newbraugh. 2000. Performance of an automatic deployable ROPS on ASAE tests. J. Agr. Saf. Health 7:51-61.

Renschler, C.S. and D.C. Flanagan. 2008. Site-specific decision-making based on RTK-GPS survey and six alternative elevation data sources: Soil erosion predictions. Trans. Amer. Soc. Agr. Biol. Eng. 51:413-424.

Spencer, H.B. and G.M. Owen. 1981. A device for assessing the safe descent slope of agricultural vehicles. J. Agr. Eng. Res. 26:277-286.
Trevett, M.F. 1962. Nutrition and growth of the lowbush blueberry. Maine Agr. Res. Sta. Bul. 151.

Vellidis, G., C.D. Perry, J.S. Durrance, D.L. Thomas, R.W. Hill, C.K. Kvien, T.K. Hamrita, and G. Rains. 2001. The peanut yield monitoring system. Trans. Amer. Soc. Agr. Eng 44:775-785.

Vitharana, U.W.A., M. van Meirvenne, D. Simpson, L. Cockx, and J. de Baerdemaeker. 2008. Key soil and topographic properties to delineate potential management classes for precision agriculture in the European loess area. Geoderma 143:206-215.

Wibawa, W.D., D.L. Dludlu, L.J. Swenson, D.G. Hopkins, and W.C. Dahnke. 1993. Variable fertilizer application based on yield goal, soil fertility, and map unit. J. Prod. Agr. 6:255-261.

Yarborough, D.E. 2004. Innovation in weed management in wild blueberry fields in Maine. Acta Hort. 715:197-202.

Zaman, Q.U., A.W. Schumann, D.C. Percival, K.C. Swain, M. Arshad, and T. Esau. 2009. Evaluation of cost-effective real-time slope sensing system for wild blueberry. Proc. $9^{\text {th }}$ European Conf. Precision Agr. Wageningen Academic Publishers, Wageningen, The Netherlands. p. $221-227$. 